\title{
An Atypical Presentation of Hemophagocytic Lymphohistiocytosis (HLH) Secondary to Occult Hodgkin Lymphoma
}

\author{
Justin Komisarof $\mathbb{C D}^{1}{ }^{1}$ Kevin McGann, ${ }^{1}$ Alissa Huston, ${ }^{1}$ Hani Katerji $\mathbb{D},{ }^{2}$ \\ and Mary Anne Morgan ${ }^{1}$ \\ ${ }^{1}$ Department of Medicine, University of Rochester Medical Center, 601 Elmwood Avenue Box MED, Rochester, NY 14642, USA \\ ${ }^{2}$ Department of Pathology and Laboratory Medicine, University of Rochester Medical Center, 601 Elmwood Avenue Box 626, \\ Rochester, NY 14642, USA
}

Correspondence should be addressed to Justin Komisarof; justin_komisarof@urmc.rochester.edu

Received 3 October 2020; Revised 5 July 2021; Accepted 19 July 2021; Published 24 July 2021

Academic Editor: Kiyotaka Kawauchi

Copyright (c) 2021 Justin Komisarof et al. This is an open access article distributed under the Creative Commons Attribution License, which permits unrestricted use, distribution, and reproduction in any medium, provided the original work is properly cited.

\begin{abstract}
Hemophagocytic lymphohistiocytosis (HLH) is a rare and life-threatening syndrome of immune system dysregulation characterized by the phagocytosis of various cells by histiocytes in the bone marrow. HLH can present in one of the two ways: primary $\mathrm{HLH}$, which is caused by mutations in genes essential to T and NK-cell function, and secondary HLH, typically caused by Epstein-Barr virus (EBV) infection or malignancy. Because of the rapid progression and high mortality of this disease, prompt diagnosis is essential to good outcomes. Here, we report the 2-month clinical course of a patient who presented with altered mental status and recurrent fever of unknown origin. Initially, he did not meet diagnostic criteria for HLH and had a negative bone marrow biopsy; however, he eventually progressed to full-blown HLH secondary to occult Hodgkin lymphoma. This case is unusual for the slow and smoldering course of the patient's disease and highlights the importance of aggressively searching for potential malignancies to ensure the initiation of definitive therapy as soon as possible.
\end{abstract}

\section{Introduction}

Hemophagocytic lymphohistiocytosis (HLH) is a rare lifethreatening syndrome of immune system dysregulation characterized by hypersecretion of inflammatory cytokines due to persistent overactivation of cytotoxic T cells and NK cells, ultimately leading to phagocytosis of hematopoietic cells by histiocytes throughout the reticuloendothelial system [1-3]. While HLH was initially described as a genetic disorder of childhood and much of what is known regarding its pathophysiology, presentation, and management has originated from the pediatric literature, our understanding of secondary HLH in adults continues to grow [4]. While the potential etiologic underpinnings of secondary HLH are exceedingly broad [5-10], principal among them are EBV infection and lymphoma $[1,11-14]$. The presentation of HLH is variable and nonspecific, overlapping with many conditions such as sepsis, thereby posing significant challenges for early diagnosis and treatment in what is often a rapidly progressive and fatal picture [15-21].

Diagnostic criteria developed from pediatric patients with familial HLH were first proposed in 1991 [22] and later revised in 2004 [23] to include eight criteria of which a patient must meet at least five: fever $\left(\geq 38.5^{\circ} \mathrm{C}\right.$ for $\geq 7$ days), cytopenias ( $\geq 2$ cell lines affected), splenomegaly $(>3 \mathrm{~cm}$ below costal margin), hypertriglyceridemia $(\geq 2 \mathrm{mmol} / \mathrm{L}$ ) and/or hypofibrinogenemia $(\leq 150 \mathrm{mg} / \mathrm{dL})$, hemophagocytosis in the bone marrow, spleen, or lymph nodes, elevated ferritin $(\geq 500 \mu \mathrm{g} / \mathrm{l})$, elevated soluble IL-2 receptor levels $(\geq 2400 \mathrm{U} / \mathrm{mol})$, and low/absent NK-cell activity. More recently, novel diagnostic criteria known as the HScore have also been developed and validated in a small population of adult patients [24]. These diagnostic criteria align with the most common presenting symptoms of HLH and include fever, splenomegaly, and cytopenias. However, an array of other presenting findings, including skin rash $[3,25,26]$, 
pulmonary symptoms such as dyspnea and cough [27], and neurologic features including encephalopathy, seizure, ataxia, and cranial nerve abnormalities have been reported [28-31]. Treatment of secondary HLH must be initiated early and aims to address the underlying precipitating disorder, with the most commonly used HLH protocol relying on etoposide, dexamethasone, and hematopoietic stem cell transplantation as mainstays of therapy [32]. For $\mathrm{HLH}$ secondary to Hodgkin lymphoma, brentuximab therapy has been reported to be successful $[33,34]$.

\section{Case Presentation}

A 63-year-old man with a history of remote Hodgkin lymphoma at age 19 years, coronary artery disease (CAD), and recent urothelial carcinoma presented to Highland Hospital with 2-3 months of intermittent fevers and confusion. His initial laboratory values were notable for anemia (hemoglobin $9.0 \mathrm{~g} / \mathrm{dL}$ ) and thrombocytopenia $(63,000$ platelets $/ \mu \mathrm{L})$ with a normal white blood cell count $(5700$ $\mathrm{WBC} / \mu \mathrm{L})$. He was hyponatremic with a sodium of $125 \mathrm{mmol} / \mathrm{L}$ and had an elevated alkaline phosphatase $(300 \mathrm{U} / \mathrm{L})$. He underwent an extensive infectious workup which was notable only for positive Epstein-Barr virus (EBV) viral PCR (7800 copies/mL) but negative EBV IgM. Hematology was consulted out of concern for a hemolytic anemia, but hemolysis labs were unremarkable with normal serum haptoglobin $(93 \mathrm{mg} / \mathrm{dL})$ and total bilirubin $(0.9 \mathrm{mg} /$ $\mathrm{dL}$ ). Reticulocyte count was not elevated (2.3\%), and schistocytes were not seen on a peripheral smear. The possibility of hemophagocytic lymphohistiocytosis (HLH) was raised at this time due to the patient's cytopenias and recurrent fever. At this time, his ferritin was elevated at $1089 \mathrm{ng} / \mathrm{mL}$ and triglycerides were elevated at $153 \mathrm{mg} / \mathrm{dL}$ but below the diagnostic cutoff for HLH. However, fibrinogen was normal, and the patient was not observed to have splenomegaly. A bone marrow biopsy was performed and did not show phagocytic histiocytes or evidence of malignancy (Figure 1). NK functional assay was sent but cancelled due to insufficient lymphocyte count. Soluble IL-2 receptor assay was ordered. The patient was treated with a 5-day course of antibiotics, and his fever curve gradually downtrended. His encephalopathy improved with the resolution of his fevers. The patient was afebrile for 72 hours and was able to be discharged from the hospital.

One month later, the patient was admitted to Strong Memorial Hospital with ongoing intermittent fevers and confusion. In the interim, he underwent a positron emission tomography (PET) scan which revealed a hypermetabolic focus in the left palatine tonsil (Figure 2). On admission, triglycerides were slightly higher at $173 \mathrm{mg} / \mathrm{dL}$ and ferritin was also slightly higher at $1407 \mathrm{ng} / \mathrm{mL}$. He had a positive blood culture for Staphylococcus epidermidis which was believed to be a contaminant. Tonsillar biopsy demonstrated an atypical clonal lymphoid population but no morphologically abnormal lymphoid cells and no Hodgkin Reed-Sternberg (HRS) cells or other evidence for lymphoma. Soluble IL-2 receptor assay from the earlier hospitalization had still not resulted at this time. Ferritin continued to rise

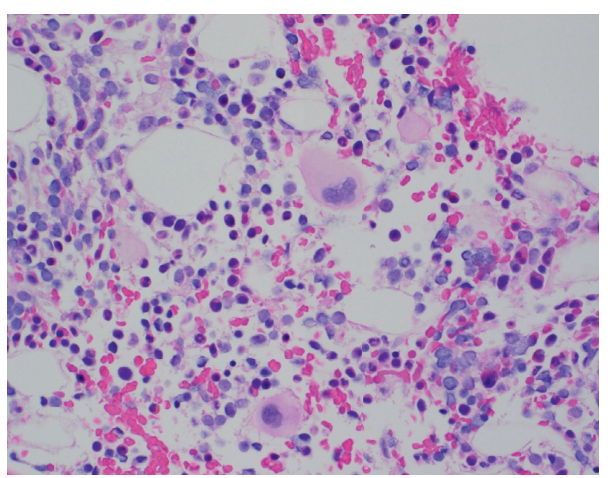

Figure 1: Hematoxylin and eosin (H\&E) section of the hypocellular bone marrow with no definitive infiltration by lymphoma.

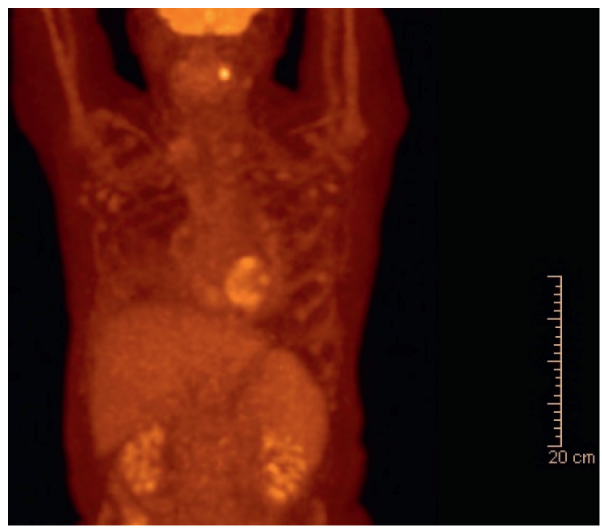

FIGURE 2: PET scan revealing the hypermetabolic focus localized to the left palatine tonsil.

climbing steadily to $9573 \mathrm{ng} / \mathrm{mL}$ two weeks after admission. The patient became hypotensive and was transferred to the ICU for vasopressor support. He developed acute hypoxic respiratory failure requiring intubation thought to be due to pleural effusions and atelectasis. Soluble IL-2 receptor came back extremely elevated at $17,375 \mathrm{U} / \mathrm{mL}$. Repeat EBV viral PCR was now 40,400 copies/mL. The patient underwent repeat bone marrow biopsy which showed Hodgkin lymphoma with hemophagocytic lymphohistiocytosis (Figure 3), confirming the diagnosis of HLH. Karyotype analysis was 46XY with no apparent clonal chromosomal aberrations, and EBER-ISH was positive. The patient was started on high-dose dexamethasone $(20 \mathrm{mg})$ daily as well as etoposide $(100 \mathrm{mg} /$ $\mathrm{mL}$ ) twice weekly. At this point, ferritin was now 12,130 ng/ $\mathrm{mL}$. Dexamethasone was increased shortly after to $40 \mathrm{mg}$ daily, and the patient received a single dose of brentuximab $(1.8 \mathrm{mg} / \mathrm{kg})$. After receiving brentuximab, the patient developed progressive renal failure with creatinine increasing from 1.4 to $3.0 \mathrm{mg} / \mathrm{dL}$ over the course of a week as well as a lactic acidosis. After discussion with the family, the patient was terminally extubated and passed away.

\section{Discussion}

Hemophagocytic lymphohistiocytosis (HLH) is a rare lifethreatening syndrome of immune system dysregulation typically seen secondary to EBV infection or blood 


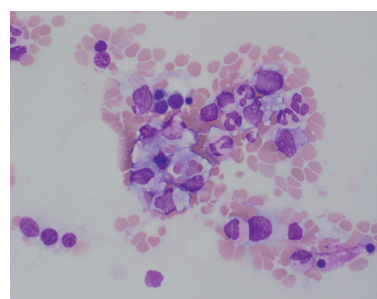

(a)

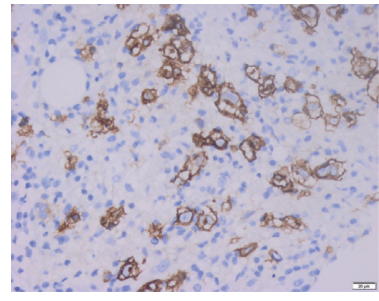

(d)

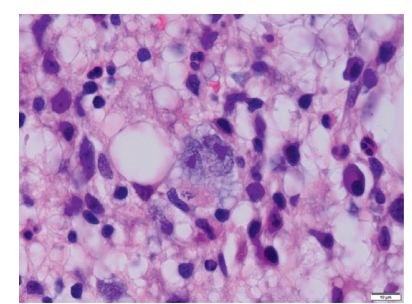

(b)

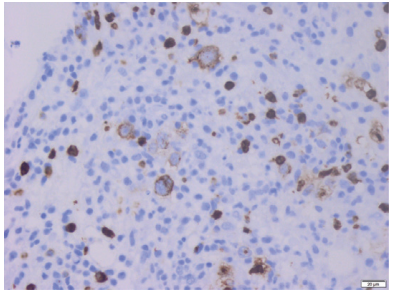

(e)

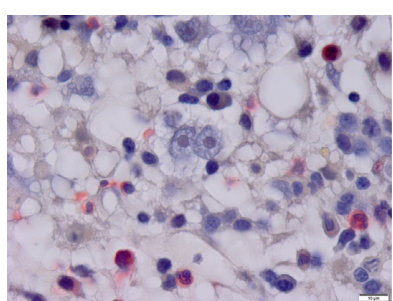

(c)

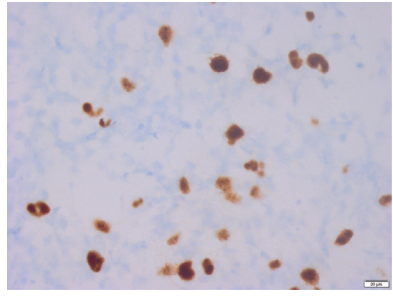

(f)

Figure 3: H\&E section of the bone marrow revealing hemophagocytosis (a). High-powered H\&E section (b) and chloracetate esterase section (c) demonstrating binucleated Reed-Sternberg (RS) cells. Immunohistochemistry showed positivity for CD30 (d) and CD15 (e) in RS cells. Epstein-Barr encoding region in situ hybridization (EBER-ISH) (f).

malignancy. Herein, we describe the detailed 2-month course of a 63-year-old male who presented with altered mental status, recurrent fevers, and fatigue and who was ultimately found to have HLH secondary to occult Hodgkin lymphoma.

This case is unusual for its slow and smoldering presentation. Typically, patients with active HLH present acutely ill, often in multiple organ system failure and requiring ICU level of care. This patient's symptoms fluctuated to an extent that he met criteria for hospital discharge, only to be readmitted four weeks later with ongoing subacute and intermittent symptoms. Although the diagnosis of HLH secondary to new lymphoma was entertained during the patient's first hospital stay, the bone marrow biopsy was unrevealing. During his second hospital stay, despite multidisciplinary subspecialty consultation and interdepartmental review, the diagnosis was clinched only when the bone marrow aspirate was repeated. As no malignant cells were found outside the bone marrow, it is possible that this represented primary bone marrow Hodgkin lymphoma. While this is quite rare and typically associated with HIV infection, for which our patient tested negative, several previous cases have been described of HIV-negative primary bone marrow Hodgkin lymphoma [35, 36]. Alternatively, it is possible that the tonsillar biopsy was a false negative and that this represented stage 4 Hodgkin lymphoma.

The most notable feature of this case that delayed diagnosis was the first bone marrow biopsy which did not show any evidence of phagocytic histiocytes or underlying malignancy. While HLH is characterized by hemophagocytosis, it is important to note that the sensitivity of bone marrow biopsy for HLH is relatively low at $83 \%$ and that hemophagocytosis can be seen in the bone marrow of patients without HLH [37]. Similarly, it is becoming clear that bone marrow biopsy false negatives are fairly common in Hodgkin lymphoma and that patients should undergo PET/
CT as part of their initial workup [38]. HLH is treated primarily with a regimen of dexamethasone and etoposide, and HLH secondary to malignancy must be treated by addressing the underlying cancer [39]. In all cases where HLH is suspected, an aggressive approach must be taken both to work up all HLH diagnostic criteria as well as to identify any underlying malignancy present and initiate definitive treatment as quickly as possible.

\section{Data Availability}

The imaging, laboratory, and pathologic data used to support the findings of this case study are included within the article.

\section{Conflicts of Interest}

All authors are employed by the University of Rochester Medical Center.

\section{Acknowledgments}

The authors would like to thank Dr. Andrew Evans for assistance with pathology figures.

\section{References}

[1] H. Al-Samkari and N. Berliner, "Hemophagocytic lymphohistiocytosis," Annual Review of Pathology: Mechanisms of Disease, vol. 13, no. 1, pp. 27-49, 2018.

[2] N. S. Bhatt, B. Oshrine, and J. An Talano, "Hemophagocytic lymphohistiocytosis in adults," Leukemia \& Lymphoma, vol. 60, no. 1, pp. 19-28, 2019.

[3] M. V. Maus, M. B. Leick, K. M. Cornejo, and V. Nardi, "Case 35-2019: a 66-year-old man with pancytopenia and rash," New England Journal of Medicine, vol. 381, no. 20, pp. 1951-1960, 2019. 
[4] M. Campo and N. Berliner, "Hemophagocytic lymphohistiocytosis in adults," Hematology/Oncology Clinics of North America, vol. 29, no. 5, pp. 915-925, 2015.

[5] C. Bailey, C. Dearden, and K. Ardeshna, "Haemophagocytic lymphohistiocytosis as a consequence of untreated B-cell chronic lymphocytic leukaemia," Case Reports, vol. 2017, 2017.

[6] J. Chen, X. Wang, P. He et al., "Viral etiology, clinical and laboratory features of adult hemophagocytic lymphohistiocytosis," Journal of Medical Virology, vol. 88, no. 3, pp. 541-549, 2016.

[7] R. Assi, P. Boddu, T. M. Kadia, Z. E. Estrov, G. GarciaManero, A. Abou Zahr et al., "Characteristics and outcomes of patients (pts) with malignancy-associated hemophagocytic lymphohistiocytosis (M-HLH) in adults: a single-center, prospective analysis of 36 pts," Blood, vol. 132, no. 1, p. 3689 , 2018.

[8] C. Y. Dumancas, H. A. G. Reyes, J. Cosico, A. Savadkar, and S. Lah, "Streptococcus pneumoniae-related hemophagocytic lymphohistiocytosis treated with IVIG and steroids," American Journal of Case Reports, vol. 19, pp. 25-28, 2018.

[9] F. E. Elzein, N. Al Sherbini, M. M. Alotaibi, and W. M. AlHassan, "Brucellosis accompanied by haemophagocytic lymphohistiocytosis and multiple splenic abscesses in a patient with depression," Case Reports, vol. 2018, 2018.

[10] C. Kennedy-Snodgrass, M. Obayomi, R. Muddasani, L. B. Slonim, and M. Braunstein, "Hemophagocytic lymphohistiocytosis secondary to babesia in an immunocompetent adult," American Journal of Hematology, vol. 94, no. 3, pp. 379-383, 2019.

[11] W. Lai, Y. Wang, J. Wang, L. Wu, Z. Jin, and Z. Wang, "Epstein-Barr virus-associated hemophagocytic lymphohistiocytosis in adults and adolescents-a life-threatening disease: analysis of 133 cases from a single center," Hematology, vol. 23 , no. 10 , pp. $810-816,2018$.

[12] C. Bigenwald, L. Fardet, P. Coppo et al., "A comprehensive analysis of Lymphoma-associated haemophagocytic syndrome in a large french multicentre cohort detects some clues to improve prognosis," British Journal of Haematology, vol. 183, no. 1, pp. 68-75, 2018.

[13] A. Iardino, Z. Amar, and Y. Ahmed, "Epstein-barr-positive classical hodgkin lymphoma-associated haemophagocytic lymphohistocytiosis: a rare case," Case Reports, vol. 2018, 2018.

[14] Z. Jin, Y. Wang, N. Wei, and Z. Wang, "Hodgkin lymphomaassociated hemophagocytic lymphohistiocytosis-a dangerous disease," Annals of Hematology, vol. 99, no. 7, pp. 1575-1581, 2020.

[15] F. G. N. Rosado and A. S. Kim, "Hemophagocytic lymphohistiocytosis," American Journal of Clinical Pathology, vol. 139, no. 6, pp. 713-727, 2013.

[16] Z. K. Otrock and C. S. Eby, "Clinical characteristics, prognostic factors, and outcomes of adult patients with hemophagocytic lymphohistiocytosis," American Journal of Hematology, vol. 90, no. 3, pp. 220-224, 2015.

[17] Z. K. Otrock, N. Daver, H. M. Kantarjian, and C. S. Eby, "Diagnostic challenges of hemophagocytic lymphohistiocytosis," Clinical Lymphoma Myeloma and Leukemia, vol. 17, pp. S105-S110, 2017.

[18] S. Birndt, T. Schenk, B. Heinevetter et al., "Hemophagocytic lymphohistiocytosis in adults: collaborative analysis of 137 cases of a nationwide German registry," Journal of Cancer Research and Clinical Oncology, vol. 146, no. 4, pp. 1065-1077, 2020.
[19] M. Zhou, L. Li, Q. Zhang et al., "Clinical features and outcomes in secondary adult hemophagocytic lymphohistiocytosis," QJM: An International Journal of Medicine, vol. 111, no. 1, pp. 23-31, 2018.

[20] J. A. Carcillo, B. Podd, and D. W. Simon, "From febrile pancytopenia to hemophagocytic lymphohistiocytosis-associated organ dysfunction," Intensive Care Medicine, vol. 43, no. 12 , pp. 1853-1855, 2017.

[21] B. C. Prokesch, S. Nagalla, F. Ezzati et al., "What's in a name? the heterogeneous clinical spectrum and prognostic factors in a cohort of adults with hemophagocytic lymphohistiocytosis," Transfusion and Apheresis Science, vol. 57, no. 6, pp. 779-784, 2018.

[22] J. I. Henter, G Elinder, and A Ost, "Diagnostic guidelines for hemophagocytic lymphohistiocytosis. The FHL study group of the histiocyte society," Seminars in Oncology, vol. 18, pp. 29-33, 1991.

[23] J.-I. Henter, A. Horne, M. Aricó et al., "HLH-2004: diagnostic and therapeutic guidelines for hemophagocytic lymphohistiocytosis," Pediatric Blood \& Cancer, vol. 48, no. 2, pp. 124-131, 2007.

[24] L. Fardet, L. Galicier, O. Lambotte et al., "Development and validation of the HScore, a score for the diagnosis of reactive hemophagocytic syndrome," Arthritis \& Rheumatology, vol. 66, no. 9, pp. 2613-2620, 2014.

[25] M. Khairoun, F. Meynen, W. Vercoutere, and H. L. Leavis, "Case series of three adult patients with exceptional clinical presentations of haemophagocytic lymphohistiocytosis," The Netherlands Journal of Medicine, vol. 78, no. 3, pp. 136-141, 2020.

[26] A. M. Schram, P. Comstock, M. Campo et al., "Haemophagocytic lymphohistiocytosis in adults: a multicentre case series over 7 years," British Journal of Haematology, vol. 172, no. 3, pp. 412-419, 2016.

[27] A. Seguin, L. Galicier, D. Boutboul, V. Lemiale, and E. Azoulay, "Pulmonary involvement in patients with hemophagocytic lymphohistiocytosis," Chest, vol. 149, no. 5, pp. 1294-1301, 2016.

[28] G. Cai, Y. Wang, X. Liu, Y. Han, and Z. Wang, "Central nervous system involvement in adults with haemophagocytic lymphohistiocytosis: a single-center study," Annals of $\mathrm{He}$ matology, vol. 96, no. 8, pp. 1279-1285, 2017.

[29] D. M. Pastula, M. Burish, G. F. Reis et al., "Adult-onset central nervous system hemophagocytic lymphohistiocytosis: a case report," BMC Neurology, vol. 15, no. 1, p. 203, 2015.

[30] S. Magaki, N. Ostrzega, E. Ho, C. Yim, P. Wu, and H. V. Vinters, "Hemophagocytic lymphohistiocytosis associated with epstein-barr virus in the central nervous system," Human Pathology, vol. 59, pp. 108-112, 2017.

[31] Y. Song, R.-J. Pei, Y.-N. Wang, J. Zhang, and Z. Wang, "Central nervous system involvement in hemophagocytic lymphohistiocytosis in adults," Chinese Medical Journal, vol. 131, no. 7, pp. 776-783, 2018.

[32] A. M. Schram and N. Berliner, "How i treat hemophagocytic lymphohistiocytosis in the adult patient," Blood, vol. 125, no. 19, pp. 2908-2914, 2015.

[33] K. Nagaharu, M. Masuya, Y. Kageyama et al., "Successful treatment of primary bone marrow hodgkin lymphoma with brentuximab vedotin: a case report and review of the literature," Journal of Medical Case Reports, vol. 12, no. 1, p. 151, 2018.

[34] B. Knox, D. Singh, H. Mai, and K. Mirza, "Hodgkin's lymphoma with HLH and complete remission with brentuximabbased therapy," BMJ Case Reports, vol. 12, no. 12, Article ID e231629, 2019. 
[35] Y. Morita, M. Emoto, K. Serizawa et al., "HIV-negative primary bone marrow hodgkin lymphoma manifesting with a high fever associated with hemophagocytosis as the initial symptom: a case report and review of the previous literature," Internal Medicine, vol. 54, no. 11, pp. 1393-1396, 2015.

[36] C. Laurent, D. A. Arber, P. Johnston, F. Fend, A. Zamo, and A. D. Attygalle, "Diagnosis of classic hodgkin lymphoma on bone marrow biopsy," Histopathology, vol. 76, no. 7, pp. 934-941, 2020.

[37] S. Goel, J. M. Polski, and H. Imran, "Sensitivity and specificity of bone marrow hemophagocytosis in hemophagocytic lymphohistiocytosis," Annals of Clinical and Laboratory Science, vol. 42, no. 1, pp. 21-25, 2012.

[38] C.-A. Voltin, H. Goergen, C. Baues et al., "Value of bone marrow biopsy in hodgkin lymphoma patients staged by FDG PET: results from the german hodgkin study group trials HD16, HD17, and HD18," Annals of Oncology, vol. 29, no. 9, pp. 1926-1931, 2018.

[39] S. Ehl, I. Astigarraga, T. von Bahr Greenwood et al., "Recommendations for the use of etoposide-based therapy and bone marrow transplantation for the treatment of HLH: consensus statements by the HLH steering committee of the histiocyte society," The Journal of Allergy and Clinical Immunology: In Practice, vol. 6, no. 5, pp. 1508-1517, 2018. 